\title{
Vector Control in Developing Countries: Challenges and Solutions
}

\author{
Claire S. Allardyce, Paul J. Dyson*, and Michael Grätzel
}

\begin{abstract}
Undoubtedly, reducing vector populations or their interactions with hosts below a critical level is a practical and proven method of disease control. Introduction of insecticide-treated bed nets has significantly reduced malaria in some parts of the world. However, for many reasons, implementation of such strategies is challenging and the protection offered by particular products limited: bed nets are only effective during sleep. Other methods have been launched, but low customer appeal, high cost, low specificity, and lack of sustainability and effectiveness are often reasons for failure. The proposed solution to these problems should also consider safety and environmental impact and be forward-thinking for continued functioning in a rapidly changing local environment. To this end, a chemical system has been identified that could be used to make an autonomous trap with chemo-attractant system.
\end{abstract}

Keywords: Energy-autonomy · Mosquito traps $\cdot$ Photovoltaics $\cdot$ Vector control

\section{Background}

There is considerable interest in products that control insects and, amongst those insects, there is a particularly high interest in mosquito control. Although mosquitoes are often considered a nuisance, they are dubbed the most dangerous animal on Earth because they are the primary vectors for major human diseases such as yellow fever, malaria and dengue fever. Their control is, therefore, a public health issue and there is a considerable economic benefit in reducing disease transmission through vector control. Consequently, there has been significant investment in developing and marketing new products to reduce the absolute numbers of insects and target breeding to collapse future populations.

The development of devices, including traps, and strategies to meet these aims has been supported by efforts to understand

${ }^{\star}$ Correspondence: Prof. P. J. Dyson

Institut des Sciences et Ingénierie Chimiques

Ecole Polytechnique Fédérale de Lausanne (EPFL)

EPFL-BCH

$\mathrm{CH}-1015$ Lausanne

E-mail: paul.dyson@epfl.ch insect behaviour to break the host-vector cycle and to develop tools to facilitate such studies. Overall, these efforts have been successful, providing a foundation on which to build disease control strategies and optimise trap design. Studies underline the importance for the optimisation of traps and their utilisation according to a number of criteria including the target species and the local environment. This knowledge has been implemented in many regions where traps combined with other technologies effectively eradicate mosquito nuisance, but these same strategies are less effective in other environments, particularly in the Global South and emergency situations, for example, refugee camps, where environmental differences reduce trap efficiency and the cost, limited distribution networks and reliance on consumables, such as gas cylinders or mains electricity, make the traps redundant.

\section{Vector Control}

Mosquito is the term used to describe any of numerous dipterous insects of the family Culicidae, a large and abundant group of insects that occurs throughout temperate and tropical regions of the world. The family includes over 3,500 species all sharing slender bodies, longlegs and a long proboscis. ${ }^{[1]}$ Only a few mosquito species can act as vectors of disease mainly because the pathogenic agent has not met with the mosquito species population. This limitation could change, particularly with widening international trade links and climate change. Amongst disease-carrying mosquitoes, only a subgroup of the species actually acts as vec- tors. As an illustration, human malaria can be transmitted by around approximately 100 of the $430 A n$. species (see Table 1 for some pertinent examples), yet in nature only 30-40 species commonly transmit the disease and of those, it is exclusively the females seeking a blood-meal to provide the nutrients for egg-laying that bite humans. Control of malaria transmission is not necessarily achieved by reducing the mosquito population; rather it is dependant only on preventing females that have mated from biting humans.

The host-seeking process involves a complex and interconnected cascade of behaviours. Each set is sensitive to different cues and stimuli and this variation is cumulative with the species-specific behaviour of mosquitoes. For example, most mosquitoes are exclusively crepuscular or nocturnal, but have specific circadian-linked times of activity leading to higher activity at dawn and dusk. Some species prefer to feed and rest indoors and others outdoors (see Table 1 for examples), although specificities can vary within the same species according to the environment, microclimate, dwelling type and also the mosquito ecotype and genetics. ${ }^{[2,3]}$

Effective control strategies reflect the target mosquito activity. For example, insecticide impregnated bed nets have had arguably the largest impact on reducing disease transmission by nocturnal, endophagic An. mosquitoes. ${ }^{[4]}$ Endophagic species can be generally reduced with improved housing construction to prevent mosquito entry, for example, screens over windows and indoor insecticides. These same strategies will have little to no effect on exophagic and exophilic species, which are best controlled through control 
Table 1. Summary for medically relevant mosquito species.

\begin{tabular}{|c|c|c|}
\hline Vector name & Associated diseases & Specificities \\
\hline \multicolumn{3}{|l|}{ Aedes (Ae.) species } \\
\hline Ae. aegypti (yellow fever mosquito) & $\begin{array}{l}\text { Dengue fever (DF), chikungunya (CHV), } \\
\text { Zika virus (ZV) and yellow fever viruses } \\
(\mathrm{YFV})\end{array}$ & $\begin{array}{l}\text { Native to Africa; now in tropical and } \\
\text { subtropical regions worldwide } \\
\text { Nocturnal }\end{array}$ \\
\hline Ae. albopictus (Asian Tiger mosquito) & $\begin{array}{l}\text { DF, CHV, ZV, YFV, several filarial } \\
\text { nematodes such as Dirofilaria immitis } \\
\text { (DHD, dog heartworm disease) }\end{array}$ & $\begin{array}{l}\text { Native to Southeast Asia; now found } \\
\text { in many countries. } \\
\text { Crepuscular }\end{array}$ \\
\hline Ae. caspius & & $\begin{array}{l}\text { Europe } \\
\text { Nocturnal }\end{array}$ \\
\hline Ae. detritus (Ochlerotatus detritus) & [Japanese encephalitis] & $\begin{array}{l}\text { Europe } \\
\text { Crepuscular }\end{array}$ \\
\hline Ae. vexans & $\begin{array}{l}\text { DHD; rabbit Myxomatosis; tahyna- } \\
\text { virus (TV; rarely diagnosed condition } \\
\text { with 2-day fever; rare complication of } \\
\text { Encephalitis) Meningitis }\end{array}$ & $\begin{array}{l}\text { Europe } \\
\text { Nocturnal }\end{array}$ \\
\hline \multicolumn{3}{|l|}{ Anopheles (An.) species } \\
\hline $\begin{array}{l}\text { An. gambiae (An. arabiensis, An. } \\
\text { bwambae, An. merus, An. melas, An. } \\
\text { quadriannulatus) }\end{array}$ & Malaria & $\begin{array}{l}\text { Africa } \\
\text { Nocturnal } \\
\text { Endophagic }\end{array}$ \\
\hline \multicolumn{3}{|l|}{ Culex $(C x$.$) species$} \\
\hline Cx. modestus & $\begin{array}{l}\text { West Nile Virus (WNV), TV and Lednice } \\
\text { virus }\end{array}$ & $\begin{array}{l}\text { Europe, Asia } \\
\text { Crepuscular }\end{array}$ \\
\hline Cx. pipiens & $\begin{array}{l}\text { Japanese encephalitis (JE), meningitis, } \\
\text { and urticaria }\end{array}$ & $\begin{array}{l}\text { Europe } \\
\text { Nocturnal }\end{array}$ \\
\hline Cx. quinquefasciatus & $\begin{array}{l}\text { JE, meningitis, urticaria, WNV } \\
\text { Emilia-Romagna, Usutu virus. }\end{array}$ & $\begin{array}{l}\text { Asia, US, Europe } \\
\text { tropical and subtropical regions of the } \\
\text { world } \\
\text { Nocturnal }\end{array}$ \\
\hline Cx. salinarius (salt marsh mosquito) & Encephalitis viruses & $\begin{array}{l}\text { Coastal areas } \\
\text { Crepuscular }\end{array}$ \\
\hline \multicolumn{3}{|l|}{ Ochlerotatus $(O$.$) species$} \\
\hline $\begin{array}{l}\text { Oc. sierrensis } \\
\text { (western tree hole mosquito) }\end{array}$ & DHD & $\begin{array}{l}\text { Europe, Australia, US } \\
\text { Nocturnal }\end{array}$ \\
\hline $\begin{array}{l}\text { Oc. taeniorhynchus } \\
\text { (black salt marsh mosquito) }\end{array}$ & $\begin{array}{l}\text { Encephalitis, Eastern Equine Encephalo- } \\
\text { myelitis Virus, DHD }\end{array}$ & $\begin{array}{l}\text { US, Central America, Caribbean region } \\
\text { to the Atlantic coast of Colombia, } \\
\text { Venezuela. } \\
\text { Nocturnal }\end{array}$ \\
\hline $\begin{array}{l}\text { Crepuscular: active at dusk or dawn } \\
\text { Nocturnal: night active }\end{array}$ & & \\
\hline
\end{tabular}

at breeding sites or along flight paths between these sites and the human hosts. Indeed, the residual disease burden of malaria in many parts of Africa is attributed to nocturnal exophilic species feeding at dusk and dawn. ${ }^{[5-7]}$

\section{Basic Trap Design}

Importantly, without optimisation, traps may draw more mosquitoes into an area than they can possibly catch, increasing the nuisance and disease transmission despite being efficient. Nevertheless, trap designs for mosquitoes have undergone relatively little development in recent years.
Many systems are variations of the same theme, which is exemplified by the Centers for Disease Control Light Trap (CDC-LT) illustrated in Fig. 1. The traps have a main body with a lure at one end, which in the case of the CDC-LT is an electric light source. A fan provides a downward draft such that mosquitoes attracted to the lure are drawn into and retained in a catching chamber. Note, mosquitoes are weak fliers so a fan can redirect flight paths. In most cases, the mosquitoes die by desiccation and are removed during the maintenance of the trap.

Although the fan is a common element in most trap designs, the claims behind its purpose vary. Some studies suggest the fan creates convection currents that simulate those around the human body, although the temperature difference is unlikely to attract mosquitoes. ${ }^{[8]}$ Others suggest the fan distributes chemo-attractants in an optimised fashion. ${ }^{[9]}$

\section{Lures}

Light was the first lure shown to attract insects and light traps have been used to attract and trap nocturnal insect species for over a century. ${ }^{[10]}$ In early traps light was emitted from a kerosene lamp. Later, electric light bulbs were used in front of a white sheet. No other trapping method has 


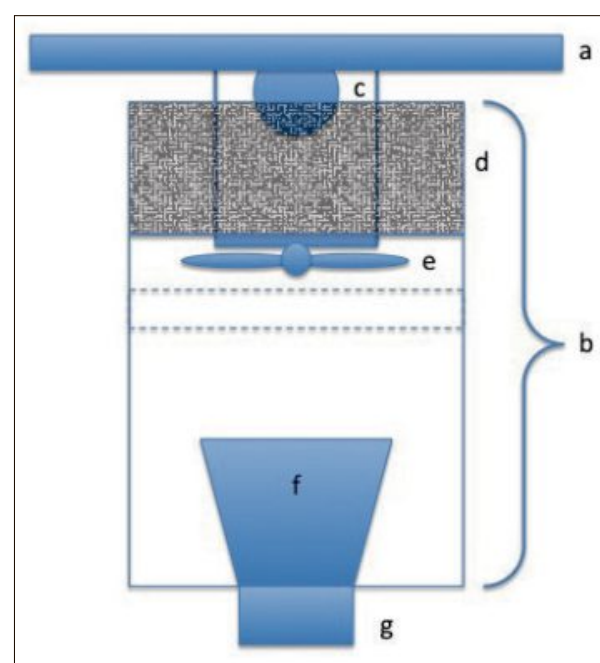

Fig. 1. Schematic diagram of a CDC Light Trap. At the top of the trap is a metal plate (a) protecting the main body (b) of the trap from rain and other damage. The light source (c) is situated under the plate and extends into the upper portion (d) of the cylindrical trap body, which is covered with a selective mesh screen to exclude larger insects, such as moths and beetles. Below the mesh is a fan (e) run by a 6 -volt battery. As the fan turns, it creates a downdraft such that mosquitos attracted to the light are drawn into the collection jar and trapped. Below the fan is a fine mesh funnel (f) that leads to the collection jar (g). Collection efficiency is improved with a $\mathrm{CO}_{2}$ source (not shown).

proved to be so consistently successful in capturing larger numbers or a greater variety of species ${ }^{[11,12]}$ and, although some disease-carrying species evade the CDCLT, ${ }^{[13]}$ these traps were used in agriculture settings with a significant impact on pest control. ${ }^{[14]}$ Indeed, many insects, including some medically important mosquito species, are attracted to light, naturally swarming in the full moon for mating. Interestingly, even after mating there is evidence to suggest that $A n$. and $C$. species are still attracted to light with the catches of CDC-LTs positioned indoors yielding approximately $95 \%$ females before feeding. ${ }^{[15]}$ This specificity is important as it implies a direct reduction in biting load in the background of studies that indicate total mosquito population reduction may have little change in biting load. ${ }^{[16,17]}$ Specificity is also becoming an increasingly important factor due to the environmental impact of non-selective insect control, including impacts on the pollination of plants and the food chain of animals. Despite the success in some environments, new insights into insect response and capture using only light as a lure is constantly under re-appraisal and assessment, a process that has considerably benefited from the development of specific analytical tools. [18]

Improved efficiency and specificity of traps has been obtained using chemo-at- tractants selective for particular insects. The majority use carbon dioxide, which has been known for decades to attract biting insects. ${ }^{[19]}$ In its simplest form, baiting can be achieved by adding a block of dry ice to the basic CDC-LT. ${ }^{[20]}$ Many of the larger traps use propane or $\mathrm{CO}_{2}$ cylinders (flow rate example $500 \mathrm{ml} / \mathrm{min}$ ). Despite competition with other focal sources of this gas, including degradation of biomass, animal respiration or plant respiration at night, the plume of $\mathrm{CO}_{2}$ produced is thought to mimic human exhalation and considerably increases both the performance and the specificity for host-seeking insects. ${ }^{[21]}$

The actual increase in trapping efficiency due to chemo-attractants varies between models, location and species targeted. In outdoor locations efficiency due to $\mathrm{CO}_{2}$ can be doubled, ${ }^{[22]}$ whereas in some indoor conditions the un-baited trap is more efficient.[15] For specificity, the addition of $\mathrm{CO}_{2}$ to CDC-LTs was shown to increase the number of biting insects approximately 3 fold with only a $10 \%$ increase in non-bloodsucking numbers. ${ }^{[23]}$ The tests were run overnight in proximity to livestock. Ae., An., and $C$. species are amongst those that seem to be systematically more effectively trapped by CDC-LT supplemented with $\mathrm{CO}_{2}{ }^{[20]}$

Further developments in efficiency and selectivity have been attained using blends of chemo-attractants. Alone, the blends offer little advantage over the un-baited trap; however, in combination with $\mathrm{CO}_{2}$ there is a synergistic effect.[24] The $\mathrm{CO}_{2}$ is thought to sensitise the insects to the blends of other chemicals, although prolonged activation has been suggested to disorientate the mosquitoes, ${ }^{[25]}$ suggesting that $\mathrm{CO}_{2}$ needs to be coupled to a lure system that quickly leads to trapping.

Several chemo-attractant blends are commercially available and essentially all contain volatile organic compounds that are produced by the host. In the case of a human host, 1-octen-3-ol is a common attractant with effective flow rates in the region of $0.5 \mathrm{mg} / \mathrm{h}$ to offer a significant increase in efficiency for capturing $A e$. albopictus. ${ }^{[26]}$ It has been suggested that this chemical and others can be obtained naturally with an effective source being foot skin residue on nylon socks. ${ }^{[27]}$ Other common chemicals in the commercial blends include ammonia, L-(+)-lactic acid and tetradecanoic acid (see Scheme 1). ${ }^{[18]}$ Supplementation with 3-methylbutanoic acid, 4,5 dimethylthiazole, 2-methyl-1-butanol, and/or 3-methyl-1-butanol in various combinations was shown to elicit both improved and less effective or inhibitory results. ${ }^{[18]}$ There is debate as to whether commercial blends are more attractive than human odour with one study suggesting blends of ammonia and carboxylic acids with a $\mathrm{CO}_{2}$ plume is $3-5$ times more attractive than human odour from male volunteers ${ }^{[28]}$ and another study concluding blends are less attractive.[29] These studies emphasise another variable in trap efficiency, i.e. competition with natural odorant sources, ${ }^{[29]}$ including both host chemo-attractants and other animals and, it is also worth noting, that many of these same chemicals are also produced by flowering plants as a form of chemical communication to promote insect-mediated pollination. ${ }^{[30]}$

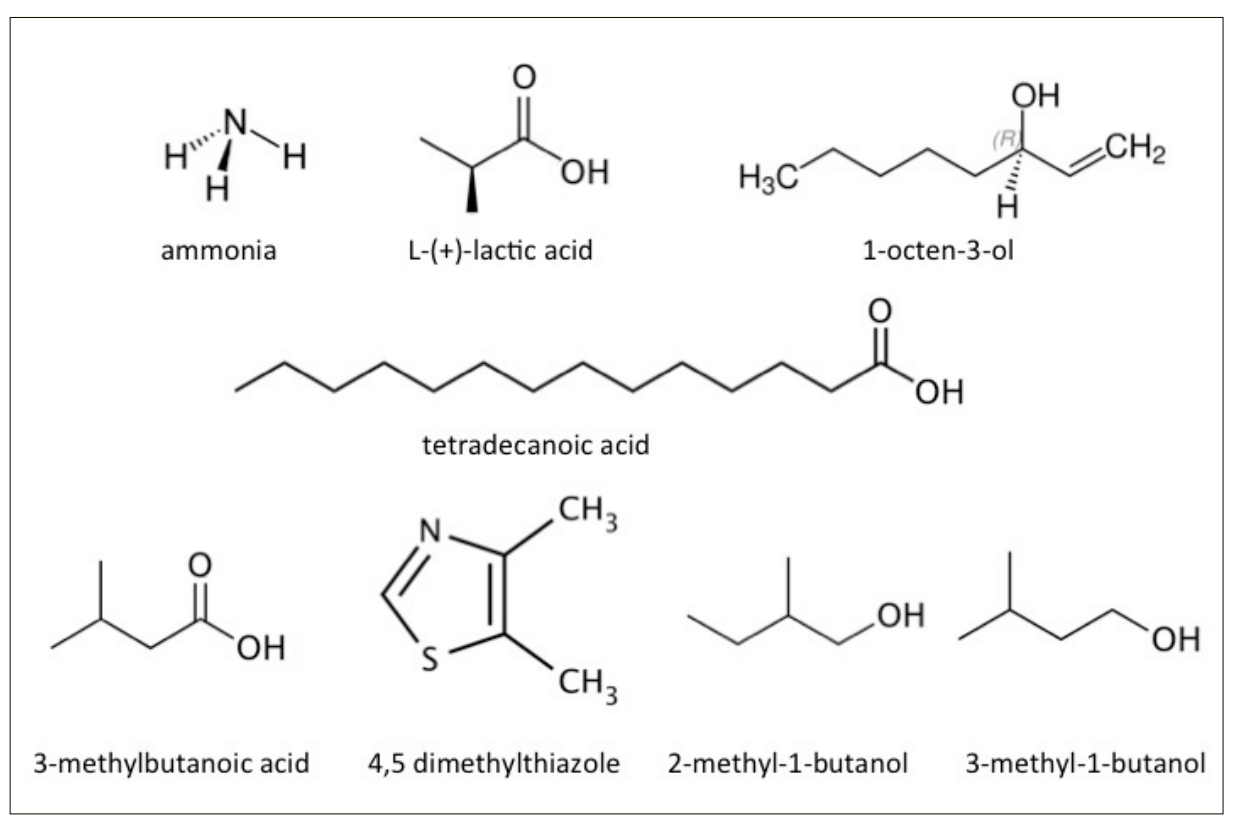

Scheme 1. Top: Common ingredients to commercial chemo-attractant chemical blends ammonia, L-(+)-lactic acid, and 1-octen-3-ol. Centre: tetradecanoic acid. Bottom: Examples of chemicals tested as supplements the standard blend 3-methylbutanoic acid, 4,5 dimethylthiazole, 2-methyl1-butanol, and/or 3-methyl-1-butanol 


\section{Energy}

The market for traps is large and well-developed and reliable amenities and distribution networks have led to a number of effective mains-operated devices with consumable lures. Some devices overcome the need for mains electricity using batteries, photovoltaic cells or propane cylinders generating enough electricity to power a fan and, where necessary, a lamp. Although more expensive than the mains-operated alternatives, operation independent of a power source, such that with multiple traps larger areas can be controlled, effectively targets exophagic and exophilic species before they come into the vicinity of human activity.

\section{Optimisation of Design}

Lure systems have been iteratively optimised for a particular purpose or species and designs specific for one application are often unsuitable for other, even closely related, environments or species. A notable example is the species specificity afforded according to the placement of the trap at either ground or canopy level. ${ }^{[21]} C$. pipiens was twice as abundant in the canopy as on the ground and the inverse was observed for Ae. caspius and Ae. Detritus, whereas $C$. modestus was equally abundant at both levels. The efficiency is, in part, due to specific activities of the mosquitoes, but is an important consideration in trap design, as some models cannot be adjusted. Similarly, a comparison of two commercially available traps in Southern Louisiana showed that species-specificity was site-dependant for catches of $C$. quinquefasciatus with simultaneously consistent catches of Ae. vexans and $C$. salinarius. ${ }^{[31]}$ This study shows the importance of the trap location to control specific species. As for trap design, in the same location observations were made in Salt Lake City that showed one trap principally captured $O$. sierrensis, whereas the other had a higher specificity for $C$. pipiens ${ }^{[32]}$ and, in another study, one trap showed significant reduction in annoyance caused by the $O$. taeniorhynchus in one location, whereas in another the same traps were less effective, ${ }^{[33]}$ exemplifying the need for the right design to attract the specific species.

In most cases, traps have been designed to serve the West where changes in the basic CDC-LT design to improve usability and efficiency come at considerable financial cost and offer little benefit to Global South situations, leaving the most vulnerable people with the weakest defences. Indeed, while the CDC-LT may be adapted for such applications at a relatively low cost with, for example, integration of a photovoltaic power source, the reliance on a $\mathrm{CO}_{2}$ consumable to tackle the current problem of exophilic malaria vectors is prohibitive. As an alternative, other locally available reagents, such as combinations of acid and bicarbonate of soda or yeast and sugar, that can generate $\mathrm{CO}_{2}$ have been trialled and shown to be more effective than un-bated traps. ${ }^{[34]}$ Nevertheless, maintenance and cost poses a problem.

\section{Design towards Autonomous Traps}

Just over a decade ago, traps containing a specific $\mathrm{TiO}_{2}$ surface were launched. The surface coupled to a UV bulb, is claimed to generate $\mathrm{CO}_{2}$ sufficient to lure biting insects. ${ }^{[35,36]}$ The trap design has the essential elements of the CDC-LT, with the lamp modified to emit UV light that interacts with the supplementary $\mathrm{TiO}_{2}$ coated photocatalytic surface above the light source to promote the oxidation of organic molecules in the air into $\mathrm{CO}_{2} \cdot{ }^{[37,38]}$ Air purification using photocatalysis across platinised $\mathrm{TiO}_{2}$ surfaces has previously been reported $[39,40]$ and, in line with this notion, the original idea of the photocatalytic traps was to provide an air-cleaning function.

Several products have been realised based on the patented technology including the Triple trap (The Kendal Group, Hubers cc, South Africa) and DynaTrap series (Dynamic Solutions Worldwide, LLC 12247 W. Fairview Ave. Milwaukee, WI 53226). Although relatively small amounts of $\mathrm{CO}_{2}$ would be produced via the photocatalytic mechanism due to the limited availability of organic matter in the air, the efficiency of the Triple Trap, for example, does not appear to be improved by additional $\mathrm{CO}_{2}$ supplements. ${ }^{[41]}$ Using mosquitoes as the carbon source to produce

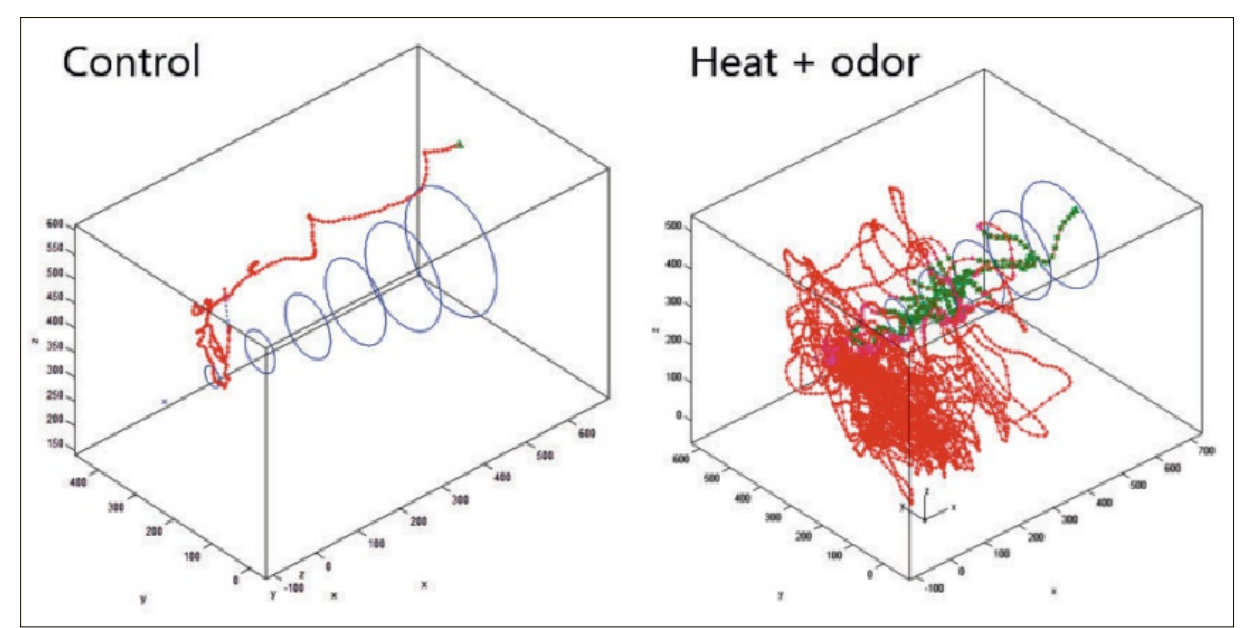

Fig. 2. Mosquito tracks in a wind tunnel. Left: standard odour plume represented by cylinders shows mosquitoes are attracted to the odour. Right: combinations of odour and heat trigger foraging flight patterns indicative of imminent biting. Images supplied by and reproduced by permission of Noldus Information Technology, Wageningen, The Netherlands.

chemo-attractant is an attractive concept, however, since mosquitoes are most active at night, a catalyst that is not photo-activated would be advantageous.

In order to produce an effective, self-supporting trap the design should ideally be optimised under specific conditions. Recent advances in tracking technologies allow mosquito behaviour to be exquisitely analysed both in the laboratory and field environments should make tailoring the trap design to different applications and locations possible. In the laboratory, behavioural mapping of mosquitoes in a wind tunnel in response to different stimuli (Fig. 2) provide a way of screening attractants. Mosquito responses have been correlated to different behaviour ${ }^{[42]}$ and such studies have yielded important information concerning attractants including heat and attractant position relative to a fan. ${ }^{[43]}$

\section{Future Directions}

As a result of these recent developments we are modifying the design of CDC-LT mosquito traps for the control of specific vectors in specific locations. Examples include the malaria vectors $A n$. species prevalent in rural parts of West Africa and refugee camps. ${ }^{[44]}$ Design for both locations shares common features: the same subgroup of insects is targeted and durability, low-maintenance, autonomous and transportable devices are favoured. In addition to the obvious location variables, the control problem differs as in established settlements in the Global South the traps target a residual disease burden, whereas the refugee camp setting requires a rapid response element that will offer independently and alongside other methods.

Our CDC-LT comprises an autonomous trap that can be assembled in the local envi- 
ronment to target the residual biting insect population. Durability, low-maintenance, autonomous and lightweight are key features for both of the above mentioned applications. The prototype product consists of a cylindrical main body, similar to the CDC-LT shown in Fig. 1, but is formed from a flexible, lightweight photovoltaic sheet (see Fig. 3). The photovoltaic material comprises a dye-sensitised solar cell (DSSC), active in diffuse light, to allow the trap to be positioned under leaf canopy or indoors and remain effective. ${ }^{[45-49]}$ The material has a dark colour and lower reflective capacity, which has been shown to attract mosquitoes ${ }^{[50,51]}$ and although species respond differently to the same visual stimuli $^{[52]}$ this particular behavioural response is more highly shared between malaria vectors, as well as other biting insects. ${ }^{[53]}$ The DSSC charges a battery inside the trap, which in turn powers an ergonomic fan, heat-pad and LED light source with wavelength specifically tuned to optimise efficiency and selectivity for disease-carrying vectors.

Autonomy can only be fully achieved with a self-replenishing $\mathrm{CO}_{2}$-based chemo-attractant source. In this trap, the chemo-attractant is generated by catalytic degradation of the captured mosquitoes, which are composed largely of chitin. Based on our initial studies on $\mathrm{C}-\mathrm{O}$ bond cleavage reactions, ${ }^{[54,55]}$ and subsequent studies on breaking-down biopolymers, ${ }^{[56-58]}$ we have designed a system that rapidly dis-

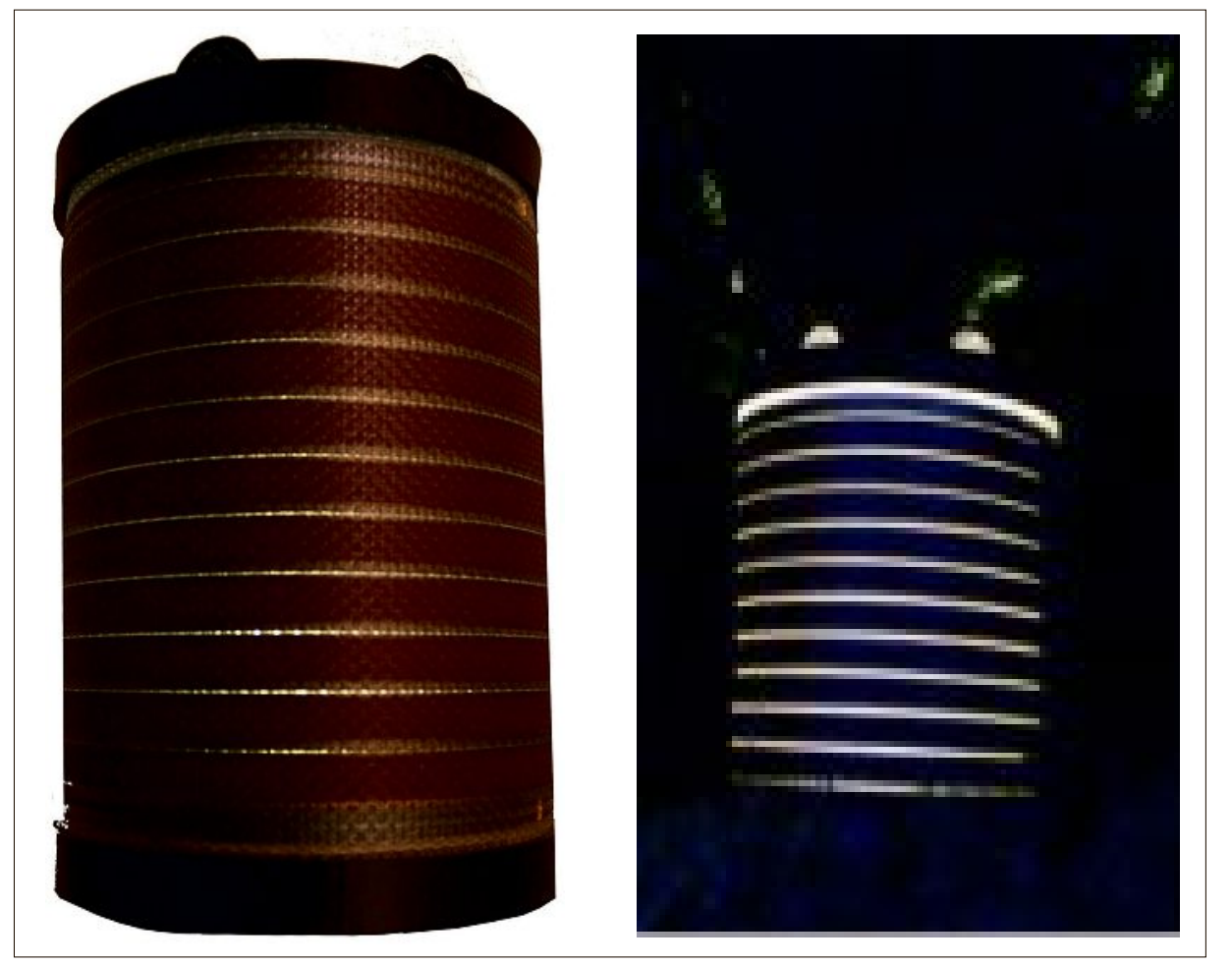

Fig. 3. Prototype autonomous mosquito trap. Left: Flexible photovoltaic material is used to form the main body of the trap and provide electricity for a heat and light lure. A chemical attractant is produced from catalytic degradation of trapped mosquitos to volatile organic compounds and $\mathrm{CO}_{2}$ and distributed via a fan. Right: Simulation study using white light LED in the field. solves mosquitoes to accelerate their degradation into volatile organic compounds (attractants) and $\mathrm{CO}_{2}$. Further optimisation of the catalytic system is in progress. Although the amounts of gas evolved is small, with the amount depending on the number of mosquitoes entering the trap, the focal distribution through trap design coupled to multiple attractant systems offers to afford an appreciable efficiency and selectivity to make the autonomous system viable to disrupt host targeting and reduce the biting load.

\section{Conclusions}

Mosquito traps represent a key technology in vector control, and while their potential is large, current data should not be over interpreted, as positive results in one environment do not automatically apply in another. Recent advances in understanding of mosquito behaviour have provided tools, including screening modelling tools, that can be used to characterised mosquito response to different attractants, which allow a new level of refinement in trap development. Nevertheless, designs must be optimised for specific applications and currently there are situations, for example, in the Global South and emergency refugee camps, where vector control is inadequate. In such environments, portability and autonomy of traps is critical due to unreliable power networks and undeveloped distribu- tion networks for components. Integration of low-cost photovoltaic materials coupled to rationally designed catalytic processing of the mosquitoes themselves could lead to the launch of a mosquito trap that targets meets the design criteria for these locations and plugs a gap in vector control, reducing parasite transmission below the critical level required to sustain the disease. Our trap meets these criteria and, importantly, it is lightweight and can be flat-packed to allow rapid distribution. The modular design allows facile assembly and adaptability and, where necessary, can be integrated with components fabricated in the local environment.

\section{Acknowledgements}

We thank Roland Bays, Medlight SA, for help designing the traps; John Meschter, G24Power (QCell) for discussion and providing the photovoltaic sheets used in the trap technology; and Nadege Krebs of Noldus Information Technology, Wageningen, The Netherlands for kindly allowing us to use the image in Fig. 2.

Received: July 12, 2016

[1] L. M. Rueda, Hydrobiologia 2008, 595, 477.

[2] B. Kesavaraju, D.A. Yee, S.A. Juliano, J. Med. Entomol. 2007, 44, 215.

[3] W. Takken, S. W. Lindsay, 'Factors affecting the vectorial competence of Anopheles gambiae: a question of scale', in 'Ecological Aspects for Application of Genetically Modified Mosquitoes', Dordrecht: Kluwer Academic Publishers, 2003, p 75-90.

[4] S. Bhatt, D. J. Weiss, E. Cameron, D. Bisanzio, B. Mappin, U. Dalrymple, K. E. Battlem, C. L. Moyes, A. Henry, P. A. Eckhoff, E. A. Wenger, Nature 2015, 526, 207.

[5] L. Durnez, M. Coosemans, in 'Anopheles mosquitoes - New insights into malaria vectors', Ed. S. Manguin, InTech, 2013. p. 671704.

[6] G. F. Killeen, Malar J. 2014, 13, 330.

[7] WHO, Guidance note: 'Control of residual malaria parasite transmission', World Health Organization Global Malaria Programme, 2014, p 5.

[8] A. E. Eiras, P. C. Jepson, Bull. Entomol. Res. 1994, 84, 207.

[9] http://www.bg-sentinel.com/ retrieved 10 June 2016.

[10] D. K. Nath, D. K. Banerjee, in 'Use of traps of pest/vector research and control', Proceedings of the national seminar held at Bidhan Chandra Krishi Viswavidyalaya, Mohanpur, West Bengal on March 10-11, Eds. S. Mukhopadhyay, M. R. Ghosh, West Bengal: Bidhan Chandra Krishi Viswavidyalaya, 1985.

[11] B. Persson, Bull. Entomol. Res. 1976, 66, 33.

[12] J. Bowden, B. M. Church, Bull. Entomol. Res. 1973, 63, 129.

[13] G. H. Rothschild, Entomol. Exp. App. 1974, 17, 294.

[14] A. W. Hartstack, J. P. Hollingsworth, D. A Lindquist, J. Econ. Entomol. 1968, 61, 546.

[15] P. Sriwichai, S. Karl, Y. Samung, S. Sumruayphol, K. Kiattibutr, A. Payakkapol, I. Mueller, G. Yan, L. Cui, J. Sattabongkot, Parasites \& Vectors 2015, 15, 1. 
[16] B. W. Collier, M. J. Perick, G. J. Boquin, S. R. Harrington, M. J. Francis, J. Am. Mosq. Control Assoc. 2006, 22, 444.

[17] J. P. Henderson, R. Westwood, T. Galloway, J. Am. Mosq. Control Assoc. 2006, 22, 401.

[18] W. R. Mukabana, C. K. Mweresa, B. Otieno, P. Omusula, R. C. Smallegange, J. J. Van Loon, W. Takken, J. Chem. Ecol. 2012, 38, 235.

[19] J. G. Logan, J. I. Cook, A. J. Mordue (Luntz), D. L. Kline, in 'Olfaction in VectorHost Interactions', Eds. W. Takken, B.G.J. Knols, Wageningen Academic Publishers, Wageningen, 2010, pp. 217-246.

[20] V. F. Newhouse, R. W. Chamberlain, J. F. Johnston, W. D. Sudia, Mosq. News 1966, 26, 30.

[21] G. L'Ambert, J. B. Ferré, F. Schaffner, D. Fontenille, J. Vector Ecol. 2012, 37, 269.

[22] I. Vythilingam, C. G. Lian, C. S. Thim, Southeast Asian J. Trop. Med. Public Health 1992, 23, 328.

[23] G. J. Venter, S. N. Boikanyo, D. M. Majatladi, L. Morey, Med. Vet. Entomol. 2016, 30, 117.

[24] T. Dekker, M. Geier, R. T. Cardé, J. Exp. Biol. 2005, 208, 2963.

[25] S. L. Turner, N. Li, T. Guda, J. Githure, R. T. Cardé, A. Ray, Nature 2011, 474, 87.

[26] J. E. Cilek, C. O. Ikediobi, C. F. Hallmon, R. Johnson, O. Okungbowa, E. N. Onyeozili, L. M. Khalil, L. Ayuk-Takem, L. M. Latinwo, U. R. Bernier, J. Am. Mosq. Control Assoc. 2012, 2, 199.

[27] L. E. Mboera, W. Takken, E. Z. Sambu, Bull. Entomol. Res. 2000, 90, 155.

[28] F. O. Okumu, G. F. Killeen, S. Ogoma, L. Biswaro, R. C. Smallegange, E. Mbeyela, E. Titus, C. Munk, H. Ngonyani, W. Takken, H. Mshinda, PloS One 2010, 5, e8951.

[29] R. C. Smallegange, B. G. Knols, W. Takken, J. Med. Entomol. 2010, 47, 338.
[30] R. L. Metcalf, M. Kogan, Crit. Rev. Plant Sci. 1987, 5,251

[31] B. W. Collier, 'Field Evaluation of Mosquito Control and Repellent Devices in Southern Lousiana', MSc Thesis, Department of Entomology, University of Wisconsin-Superior, WI 1987, May 2004.

[32] http://www.mosquito.org/traps retrieved June 10, 2016.

[33] D. L. Kline, J. Am. Mosq. Control Assoc. 2006, 22, 490.

[34] D. F. Hoel, J. C. Dunford, D. L. Kline, S. R. Irish, M. Weber, A. G. Richardson, C. W. Doud, R. A. Wirtz, J. Am. Mosq. Control Assoc. 2015, $31,248$.

[35] K.-W. Lee, Y.-H. Kim, US Patent: 2001-43847, Jul. 20, 2001.

[36] K. W. Lee, J. Korean Soc. Precision Eng. 2002, 19, 155.

[37] A. P. Boyes, S. Raymahasay, A. T. Sulidis, J. M. Winterbottom, WIT Trans. Ecol. Env. 1970, 13.

[38] A. Fujishima, T. N. Rao, D. A. Tryk, J. Photochem. Photobiol. C: Photochem. Rev. 2000, 1,1 .

[39] I. Izumi, W. W. Dunn, K. O. Wilbourn, F. R. Fan, A. J. Bard, J. Phys. Chem. 1980, 84, 3207.

[40] K. Kogo, H. Yoneyama, H. Tamura, J. Phys. Chem. 1980, 84, 1705.

[41] G. J. Venter, K. Labuschagne, S. N. B. Boikanyo, L. Morey, J. South African Vet. Assoc. 2013, 84, 5.

[42] N. C. Angarita-Jaimes, J. E. Parker, M. Abe, F. Mashauri, J. Martine, C. E. Towers, P. J. McCall, D. P. Towers, J. R. Soc. Interface 2016, 13, 20150974.

[43] J. Spitzen, C. W. Spoor, F. Grieco, C. ter Braak, J. Beeuwkes, S. P. van Brugge, S. Kranenbarg, L. P. Noldus, J. L. van Leeuwen, W. Takken, PLoS One 2013, 8, e62995.
[44] M. A. Connolly, M. Gayer, M. J. Ryan, P. Salama, P. Spiegel, D. L. Heymann, Lancet 2004, 364, 1974.

[45] S. Mathew, A. Yella, P. Gao, R. Humphry-Baker, B. F. Curchod, N. Ashari-Astani, I. Tavernelli, U. Rothlisberger, M. K. Nazeeruddin, M. Grätzel, Nature Chem. 2014, 6, 242.

[46] I. Stengel, N. Pootrakulchote, R. R. Dykeman, A. Mishra, S. M. Zakeeruddin, P. J. Dyson, M. Grätzel, P. Bäuerle, Adv. Energy Mater. 2012, 2, 1004.

[47] M. P. Antony, T. Moehl, M. Wielopolski, J. E. Moser, S. Nair, Y. J. Yu, J. H. Kim, K. Y. Kay, Y. S. Jung, K. B. Yoon, C. Grätzel, S. M. Zakeeruddin, M. Grätzel, ChemSusChem. 2015, 8,3859 .

[48] A. Mishra, N. Pootrakulchote, M. Wang, S.J. Moon, S.M. Zakeeruddin, P. Bäuerle, M. Grätzel, Adv. Func. Mater. 2011, 21, 963.

[49] G. P. S. Lau, J.-D. Decoppet, T. Moehl, S. M. Zakeeruddin, M. Grätzel, P. J. Dyson, Sci. Rep. 2015, 5, 18158

[50] Y. T. Qiu, R. C. Smallegange, J. J. Van Loon, C. J. Ter Braak, W. Takken, Med. Vet. Entomol. 2006, 20, 280.

[51] G. A. Brett, Trans R. Soc. Trop. Med. Hyg. 1938, 32, 113.

[52] I. H. Gilbert, H. K. Gouck, J. Econ. Entomol. 1957, 50, 678.

[53] W. L. Sippel, A. W. A. Brown, Bull. Entomol. Res. 1953, 43, 567.

[54] N. Yan, C. Zhao, C. Luo, P. J. Dyson, H. Liu, Y. Kou, J. Am. Chem. Soc. 2006, 128, 8714.

[55] N. Yan, Y. Yuan, R. Dykeman, Y. Kou, P. J. Dyson, Angew. Chem. Int. Ed. 2010, 49, 5549.

[56] S. Siankevich, Z. Fei, N. Yan, P. J. Dyson, Chimia 2015, 69, 592.

[57] N. Yan, C. Zhao, P. J. Dyson, C. Wang, L.-t. Liu, Y. Kou, ChemSusChem. 2008, 1, 626.

[58] S. Siankevich, Z. Fei, R. Scopelliti, P. Jessop, J. Zhang, N. Yan, P. J. Dyson, ChemSusChem 2016, 9, 2089. 